\title{
Safety and Efficacy of Sofosbuvir Based Regimens in Treating Chronic Hepatitis C Virus in Egyptian Patients: Real World Study: Single Center Experience
}

\author{
Mohamed Abbasy ${ }^{1}$, Tamer Abou Elela ${ }^{2}$, Olfat Hendy ${ }^{3}$, Omkolsoum \\ Al-Haddad ${ }^{1}$, Ehab Darwiesh ${ }^{4}$, Tary Salman ${ }^{1}$, Talat Zakareya ${ }^{1}$ \\ ${ }^{1}$ Department of Hepatology, National Liver Institute, Menoufia University, Egypt \\ ${ }^{2}$ Department of Gastroenterology, National Hepatology and Tropical Medicine \\ Research Institute, Egypt \\ ${ }^{3}$ Department of Clinical Pathology, National Liver Institute, MenoufiaUniversity, \\ Egypt. \\ ${ }^{4}$ Department of Tropical Medicine, Faculty of Medicine, Zagazig University, Egypt .
}

Corresponding Author Ehab Darwiesh

\section{Mobile:}

00201015956627

E mail:

ehab_drwish_123@ya hoo.com

Key words:

Hepatitis C Virus; Sofosbuvir; Egyptian patients; Compensated liver disease
Backgroundand study aims:Hepatitis C virus (HCV) is the main leading cause of liver disease in Egypt. A new era of HCV treatment has been started with the evolution of direct acting antiviral agents. Sofosbuvir (SOF)-based therapy was introduced by the Egyptian ministry of health in 2014 in an attempt to decrease disease burden. We aimed to evaluate efficacy and safety of Sofosbuvir-based regimens in HCV Egyptian patients with compensated liver disease.

Patients and Method:This study was conducted in National Liver Institute, MenoufiaUniversity, Egypt. Seven hundred patients out of seven hundred fifty-eight chronic $\mathrm{HCV}$ patients with compensated liver disease who met the inclusion criteria were included. According to treatment regimen patients were divided to 4 groups; group 1

\section{INTRODUCTION}

Chronic hepatitis $\mathrm{C}$ virus (HCV) infection is one of the most important clinical and public health problems. In 2015, the Center for Disease Control (CDC) estimated that 170 million people worldwide are chronically infected with HCV [1]. Although about $20 \%$ of infected individuals spontaneously clear the virus without treatment, approximately $80 \%$ will develop chronic HCV infection[1].

The major burden of $\mathrm{HCV}$ infection comes from sequelae following the chronic infection. Because patients with chronic infection are at risk of developing liver diseases including cirrhosis and liver cancer, with received Sofosbuvir (SOF), Pegylated interferon (PEG-IFN) plus ribavirin (RBV), group 2 received SOF plus RBV, group 3 received SOF and Simeprevir \pm RBV, group 4 received SOF and Daclatasvir \pm RBV.

Results:The overall SVR was 90.9\%, $81.5 \%, 95 \%$ and $98 \%$ in groups $1,2,3$, and 4 respectively. SVR in patients with liver cirrhosis was 90.56, 79.16, 95 and $96 \%$ in the 4 groups respectively. In treatment experienced patients, SVR was $86.8 \%$ in group $1,78.3 \%$ in group 2, $100 \%$ in group 3 and $86.7 \%$ in group 4 .

Conclusion: Sofosbuvir plus daclatasvir with or without ribavirin is the safest andmost effective SOF-based regimen in treatment of HCV Egyptian patients with compensated liver disease.

350,000 annual deaths due to all HCV-related causes [2].

The standard of care to treat $\mathrm{HCV}$ infection was injection of pegylated interferon (PEG-IFN) and daily ribavirin. This regimen was expensive, toxic, complicated to deliver and its cure rates were less than $50 \%$, especially for people with cirrhosis [3]. Now, most people can be cured of HCV infection with the new oral direct-acting antivirals DAAs; that target different steps of the lifecycle of HCV. Numerous clinical trials and clinical practice have shown thatDAAs are very effective and well tolerated[4]. 
In 2011, the first-generation of DAAs was introduced with two drugs boceprevir and telaprevir. Later, in 2013, approval of the second-generation DAA, NS5B polymerase inhibitor sofosbuvir (SOF), has been a further step forward. Sofosbuvir has pan-genotypic effect on HCV with better pharmacokinetics and improved resistance profiles [5]. Sofosbuvir based DAAs are safe, effective, and well tolerated in patients with chronic hepatitis $\mathrm{C}$ patients [6].

In the current study we aimed to evaluate the safety and efficacy of different Sofosbuvir (SOF) based regimens among Egyptian patients with compensated HCV related chronic liver disease.

\section{PATIENTS AND METHODS}

At national liver institute, Menoufia, Egypt, 758 patients with $\mathrm{HCV}$ related compensated liver disease have been enrolled in the present study in the period between 2015 to 2016. Patients included in the current study were HCV compensated liver diseases. HCV was diagnosed by positivity for both $\mathrm{HCV}$ antibody and $\mathrm{HCV}$ RNA by PCR.

Patients were divided into 4 groups according to treatment regimen applied for each group; group 1 received SOF, PEG-IFN plus RBV for 12 weeks, group 2 received SOF plus RBV for 24 weeks, group 3 received SOF and Simeprevir (SIM) with or without RBV for 12-24 weeks according to the state of fibrosis (presence or absence of cirrhosis) and treatment status (naïve or experienced), group 4 SOF and Daclatasvir with or without RBV for 12-24 weeks according to the state of fibrosis and treatment status. The selection of patients for each group followed the national guidelines during the study period as well as availability of the given medications.

Dosing of the used medications were scaled as the following; PEG-IFN, $1000 \quad \mu \mathrm{g}$ subcutaneously once weekly, RBV, $1200 \mathrm{mg} /$ day for those equal or more than $75 \mathrm{~kg}$ body weight and $1000 \mathrm{mg} /$ day for those weighing less than $75 \mathrm{~kg}$, SOF, $400 \mathrm{mg}$ once daily, SIM, $150 \mathrm{mg}$ once daily and daclatasvir $60 \mathrm{mg}$ once daily.

Transient elastography (FibroScan) has been used to evaluate the state of fibrosis; F1 was considered if reading was less than $7.0 \mathrm{kPa}, \mathrm{F} 2$ was considered if reading ranged between 7.0 and $9.5 \mathrm{kPa}$, while $\mathrm{F} 3$ was considered if reading was equal or higher than $9.5 \mathrm{kPa}$ and less than $12.0 \mathrm{kPa}$ and finally $\mathrm{F} 4$ was considered if reading was equal or higher than $12.0 \mathrm{kPa}$.

Patients were subjected to full laboratory panel, conventional abdominal ultrasonography and Child Turcotte Pugh (CTP) score was calculated for each patient. Diagnosis of cirrhosis based on clinical, laboratory, ultrasonic as well as FibroScan findings (and biopsy results if available).

Patients with CTP more than 8 , bilirubin more than $3.0 \mathrm{mg} / \mathrm{dl}$, or impaired kidney functions with estimated glomerular filtration rate (eGFR) less than $30 \mathrm{ml} / \mathrm{min}$ were ruled out. Patients coinfected with HBV or HIV were also excluded.

Active hepatocellular carcinoma (HCC) or recently treated $\mathrm{HCC}$ of less than 4 weeks elapsed after successful treatment has been ruled out. Active extrahepatic malignancy or treated patients who did not reach at least 2 years of disease-free survival have been also excluded.

Negative HCV RNA12 weeks after end of treatment (SVR12) was the end point used to assess treatment efficacy. All adverse events have been reported in each group.

\section{Ethics approval and consent to participate}

The study was approved by the ethics committee of National Liver Institute (NLI), Menoufia University. A signed written informed consent was taken from all patients before participation in the study.

\section{Statistical analysis methods}

SPSS, version 20 for windows (Inc, Chicago, IL, USA) was used for all statistical analyses. Qualitative data were presented as frequency and percentage. Chi square and Fisher's exact tests were used to compare groups. Quantitative data were presented as mean and standard deviation. Student t-test and Wilcoxon rank-sum test were used to compare non- parametric data. The statistical significance was set at P-value of less than 0.05 for all tests.

\section{RESULTS}

Fifty-eight patients did not fulfill the inclusion criteria, so 700 out of 758 patients were only included; group 1 included 159 patients, group 2 included 138 patients, group 3 included 201 patients and group 4 included 202 patients. 
The mean age was $49.36 \pm 9.19,54.58 \pm 9.28$, $49.46 \pm 11.4$ and $50.25 \pm 10.8$ years in group $1,2,3$ and 4 respectively. The baseline data of the studied patients are shown in table 1 . In the current study 156 patients were compensated cirrhosis, while 544 patients were non-cirrhotic.

Previous HCV treatment with IFN or peginterferon (PEG) associated with ribavirin (RIB) was recorded for $116(16.6 \%)$ patients, the remaining patients $584(83.4 \%)$ had not been previously treated.

The overall SVR in group 1 was $90.97 \%$ with a quite similar rate among cirrhotic patients $(90.56 \%)$ and a slightly lower rate in treatment experienced patients $(86.8 \%)$. In group 2, SVR was $81.5 \%$ with slightly lower rates among cirrhotic and treatment experienced patients; 79.16 and $78.3 \%$ respectively. In group 3, SVR was similar to the overall SVR; 95 and $95.5 \%$ respectively. Surprisingly it was $100 \%$ in treatment experienced patients. In group 4, the overall SVR was $98 \%$ with slightly lower rates among cirrhotic $(96 \%)$ while in treatment experienced patients it dropped down to $86.7 \%$.

The overall SVR and SVR in difficult to treat patients (cirrhotic and treatment experienced) in the studied groups are shown in figure 1.
The overall SVR was significantly different among the studied groups $(\mathrm{p}<0.001)$ with highest rate in group 4. Similarly, SVR in cirrhotic patients was significantly different among the studied groups $(p<0.001)$ with highest rate in group 4. Finally, SVR in treatment experienced patients was significantly different among the studied groups $(p<0.001)$ with highest rate in group 3.

Adverse events were reported in 89 (55.97\%), 82 $(59.42 \%), 88(40.79 \%)$ and $19(9.4 \%)$ in group 1 , 2,3 and 4 respectively. The rate of adverse events was significantly different among the studied groups $(\mathrm{p}<0.001)$ with lowest rate in group 4. The most common reported adverse events in group 1 were flu like illness $(15.1 \%)$ and anemia (12.6\%). In group2, anemia and hyperbilirubinemia were the most frequent side effects; 18.8 and $18.1 \%$ respectively. In group 3, hyperbilirubinemia and fatigue were the main adverse events; 11.9 and $6.5 \%$ respectively. In group 4, only two adverse events have been reported; hyperbilirubinemia (5.9\%) and anemia $(3.5 \%)$.

Reported adverse events in the studied groups are depicted in figure 2 
Table (1): Baseline data of the studied patients.

\begin{tabular}{|c|c|c|c|c|c|c|}
\hline & & $\begin{array}{l}\text { Group 1 } \\
(\mathrm{n}=159)\end{array}$ & $\begin{array}{l}\text { Group 2 } \\
(\mathrm{n}=138)\end{array}$ & $\begin{array}{l}\text { Group 3 } \\
(\mathrm{n}=201)\end{array}$ & $\begin{array}{l}\text { Group 4 } \\
(\mathrm{n}=202)\end{array}$ & $\begin{array}{c}\mathbf{P} \\
\text { value }\end{array}$ \\
\hline \multirow[t]{2}{*}{ Age (years) } & Range & $21-60$ & $22-70$ & $18-70$ & $19-70$ & \multirow[b]{2}{*}{0.564} \\
\hline & mean \pm SD & $49.36 \pm 9.19$ & $54.58 \pm 9.28$ & $49.46 \pm 11.40$ & $50.25 \pm 10.8$ & \\
\hline \multirow[t]{2}{*}{ Sex } & $\begin{array}{l}\text { Males } \\
\mathrm{N}(\%) \\
\end{array}$ & $133(83.6)$ & $106(76.8)$ & $152(75.6)$ & $127(62.9)$ & 0.047 \\
\hline & \begin{tabular}{|l|} 
Females \\
$\mathrm{N}(\%)$ \\
\end{tabular} & $26(16.4)$ & $32(23.2)$ & $49(24.4)$ & $75(37.1)$ & 0.024 \\
\hline \multirow[t]{2}{*}{$\begin{array}{l}\text { Treatment } \\
\text { status }\end{array}$} & $\begin{array}{l}\text { Naïve } \\
\mathrm{N}(\%) \\
\end{array}$ & $120(75.5)$ & $114(82.6)$ & $163(81.1)$ & $187(92.6)$ & 0.030 \\
\hline & \begin{tabular}{|l} 
Experienced \\
$\mathrm{N}(\%)$
\end{tabular} & $39(24.5)$ & $24(17.4)$ & $38(18.9)$ & $15(7.4)$ & 0.642 \\
\hline \multirow{3}{*}{$\begin{array}{l}\text { Fibrosis } \\
\text { stage } \\
\text { (Fibroscan) }\end{array}$} & \begin{tabular}{|l|}
$\mathrm{F} 0-2$ \\
$\mathrm{~N}(\%)$ \\
\end{tabular} & $49(30.8)$ & $15(10.9)$ & 99 (49.3) & $101(50)$ & 0.010 \\
\hline & \begin{tabular}{|l|}
$\mathrm{F} 3-4$ \\
$\mathrm{~N}(\%)$ \\
\end{tabular} & $110(69.2)$ & $123(89.1)$ & $102(50.7)$ & $101(50)$ & 0.441 \\
\hline & $\begin{array}{l}\text { Cirrhotic } \\
\text { liver }\end{array}$ & $32(20.1)$ & $41(28.9)$ & $44(21.8)$ & $39(19.3)$ & 0.092 \\
\hline \multicolumn{7}{|c|}{ Laboratory data } \\
\hline \multicolumn{2}{|c|}{$\mathrm{AST}(\mathrm{U} / \mathrm{L})$} & $56.81 \pm 41.6$ & $71.61 \pm 48.02$ & $54.85 \pm 36.9$ & $59.8 \pm 39.5$ & 0.180 \\
\hline \multicolumn{2}{|c|}{ ALT (U/ml) } & $71.03 \pm 70.8$ & $64.7 \pm 44.21$ & $57.15 \pm 38.9$ & $64.4 \pm 45.6$ & 0.410 \\
\hline \multicolumn{2}{|c|}{ Total bilirubin (mg/dl) } & $0.77 \pm 0.27$ & $1.05 \pm 0.56$ & $0.82 \pm 0.44$ & $0.92 \pm 0.52$ & 0.332 \\
\hline \multicolumn{2}{|c|}{ Albumin $(\mathrm{g} / \mathrm{L})$} & $4.25 \pm 0.45$ & $3.8 \pm 0.51$ & $4.13 \pm 0.56$ & $4.01 \pm 0.55$ & 0.630 \\
\hline \multicolumn{2}{|c|}{ Creatinine $(\mathrm{mg} / \mathrm{dl})$} & $0.85 \pm 019$ & $0.84 \pm 0.21$ & $0.84 \pm 0.18$ & $0.85 \pm 0.19$ & 0.882 \\
\hline \multicolumn{2}{|c|}{ INR } & $0.9 \pm 0.27$ & $1.0 \pm 0.15$ & $0.9 \pm 0.3$ & $0.95 \pm 0.1$ & 0.738 \\
\hline \multicolumn{2}{|c|}{$\mathrm{Hb}(\mathrm{g} / \mathrm{dl})$} & $14.74 \pm 1.57$ & $13.66 \pm 1.81$ & $14.09 \pm 1.86$ & $13.56 \pm 1.7$ & 0.692 \\
\hline & & $6.89 \pm 2.0$ & $5.57 \pm 1.89$ & $6.61 \pm 2.28$ & $5.99 \pm 1.93$ & 0.584 \\
\hline \multicolumn{2}{|c|}{$\begin{array}{l}\text { WBC } \mathrm{s}\left(\mathrm{C} / \mathrm{mm}^{3}\right) \\
\text { Platelets }\left(\mathrm{C} / \mathrm{mm}^{3}\right)\end{array}$} & $198.7 \pm 46.5$ & $122.27 \pm 55.1$ & $181 \pm 67.09$ & $188 \pm 77.8$ & 0.039 \\
\hline \multicolumn{2}{|c|}{ HCV RNA (IU/ml) } & $1724399 \pm 3086862$ & $1155007 \pm 2968751$ & $1678010 \pm 2415389$ & $1468920 \pm 2494531$ & 0.028 \\
\hline
\end{tabular}

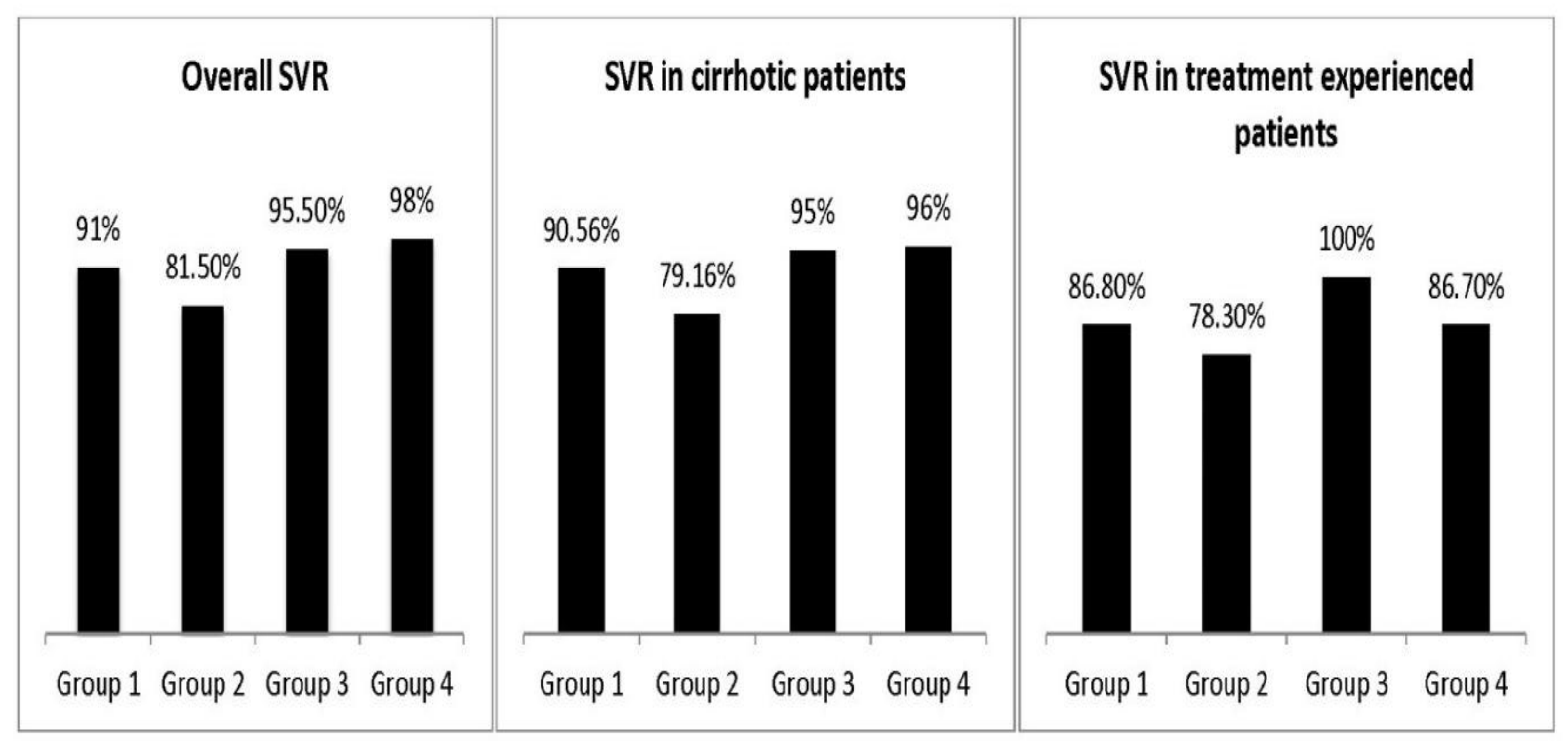

Figure (1): The overall SVR and SVR in cirrhotic and treatment experienced patients. 


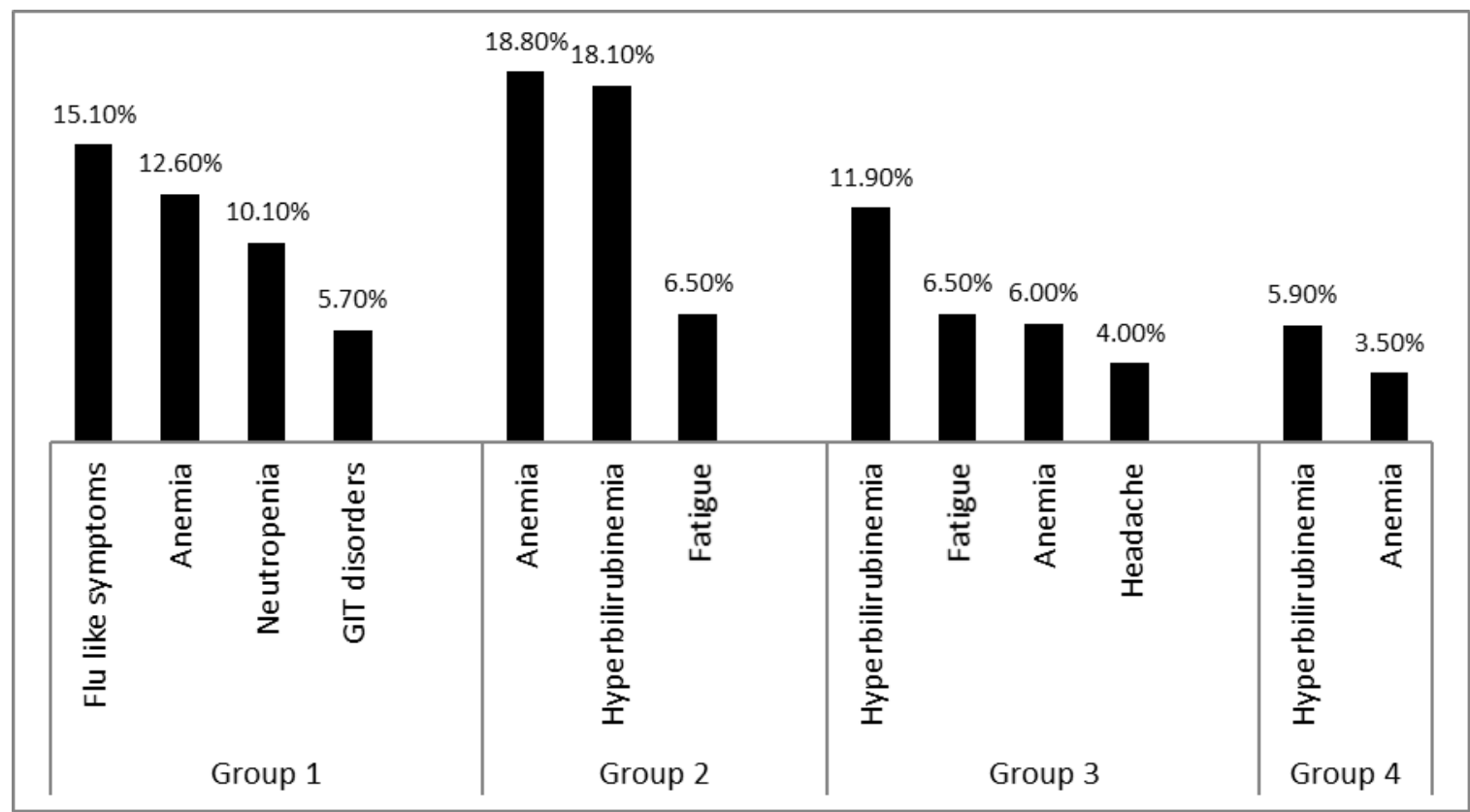

Figure (2):The reported adverse events in the studied groups.

\section{DISCUSSION}

$\mathrm{HCV}$ is a leading cause of chronic liver disease worldwide and a major health burden [7]. HCV affects approximately 170-180 million people (2-3\% of the global population) [8].Due to the widespread schistosomiasis treatment campaigns, Egypt has the highest HCV prevalence in the world, reaching $12 \%$ [9].

The main goal of chronic hepatitis $\mathrm{C}$ therapy is to eradicate the virus, characterized by sustained virological response (SVR), with subsequent decrease of the liver damage and $\mathrm{HCV}$ transmission [10].

The previous standard treatment for chronic hepatitis $\mathrm{C}$ (CHC) patients, comprising a combination of PEG-IFN and ribavirin, was associated with severe adverse reactions and suboptimal efficacy [11].

The use of DAAs represents a major advance in CHC therapy, including advances in patients who are intolerant and/or refractory to interferon. The association of DAAs showed SVR rates between 80 and $100 \%$ depending ongenotype, previous treatment of $\mathrm{CHC}$ and the presence of cirrhosis [12]. Sofosbuviris a selective, pangenotypic nucleotide inhibitor of NS5B-directed HCV RNA replication. SOF based treatment was proved to be safe and well tolerated in clinical trials $[13,14]$.

Thus, in this study, we aimed to study initial virological response to SOF based treatment regimens (SOF, RBV and Peg IFN- $\alpha / \mathrm{SOF}$ and RBV alone/ SOF and Simeprevir/ SOF and Daclatasvir) and describe important real-life data from 700 patients.

In this study the overall SVR in group 1 who received SOF, PEG-IFN plus RBV for 12 weeks was $90.97 \%$ with a quite similar rate among cirrhotic patients $(90.56 \%)$ and a slightly lower rate in treatment experienced patients $(86.8 \%)$.

These results are similar to that of Lawitz et al [15], who found overall rate of SVR of $89 \%$ in HCV patients who received Sofosbuvir with peginterferon-ribavirin

But it is higher than that reported by Wehmeyer et al [16], who found thatSVR12 SOF/Pegylated interferon/Ribavirin in patients infected with HCV genotype 3 to be $80.6 \%$ in treatment naïve patients, $81.0 \%$ in cirrhotic patients and $80.8 \%$ in treatment experienced patients.

In this study the lowest overall response rate was in group 2 patients who received SOF plus RBV for 24 weeks. SVR was $81.5 \%$ with slightly lower rates among cirrhotic and treatment experienced patients; 79.16 and $78.3 \%$ respectively. In another study from Egypt using sofosbuvir and ribavirin for treatment of $\mathrm{CHC}$ infection, the SVR12 was $88.6 \%$ in treatment naïve patients and $76.7 \%$ in treatment experienced patients. This study also mentioned that, patients with cirrhosis had lower rates of SVR12 than those without cirrhosis $(75 \%$ versus 89.7\%) [17]. 
Indeed, the combination of interferon and ribavirin with sofosbuvir in treatment of $\mathrm{HCV}$ in this study was based on guidelines for treatment of genotype $4 \mathrm{HCV}$ issued in 2014 by the American Association for the Study of Liver Diseases (AASLD), European Association for the Study of the Liver (EASL), and World Health Organization (WHO) which included sofosbuvir administered in combination with Peg-IFN $\alpha$ and RBV for 12 weeks or an interferon-free regimen of sofosbuvir in combination with RBV for 24 weeks [18-20].

In 2018 and onwards, the situation has been changed. Interferon-free, ribavirin free, DAAbased regimens became the best options in HCVinfected patients without cirrhosis (and in those with compensated cirrhosis), including "treatment-naïve" patients and "treatmentexperienced" patients [20].

The National Committee for Control of Viral Hepatitis (NCCVH, Cairo, Egypt) program discontinued interferon-based therapy and introduced interferon-free all-oral treatment protocols, incorporating DAAs from different classes.

IFN-free regimens are becoming the new standard of care for $\mathrm{CHC}$ patients and on the other hand, combination of sofosbuvir plus ribavirin alone is no more recommended in by current guidelines because of frequent side effects of ribavirin and somewhat lower SVR rate than other DAAs combinations [21].

In group 3 patients, who received SOF and Simeprevir with or without RBV for 12-24 weeks, the SVR was; 95\%, while in cirrhotic patients it was $95.5 \%$. Surprisingly it was $100 \%$ in treatment experienced patients.

These results are near to that obtained by Yosry et al[6], who found that, SVR12 was achieved in $94.7 \%$ in patients who received SOF/SMV for treatment of hepatitis $\mathrm{C}$ virus recurrence post living donor liver transplant.

Indeed, the highest overall SVR in this study was seen in group 4, who were given SOF and Daclatasvir with or without RBV for 12-24. The overall SVR was $98 \%$ with slightly lower rates among cirrhotic $(96 \%)$ while in treatment experienced patients $(86.7 \%)$.

These results are similar to that obtained by other studies as Yosry et al. [6], Ahmed et al.[22], and Omar et al [23], who found SVR12 in Egyptian patients treated with Sofosbuvir plus Daclatasvir to be $100 \%, 96 \%$ and $95.4 \%$ respectively.

The SVR in patients with cirrhosis in group 3 was $95 \%$ and group 4 was $96 \%$ in our study. These rates are higher than that reported by Kutala et al [24], (73\%) as well as those reported in OPTIMIST-2 [25] and ALLY-3 [26] clinical trials.

The highestSVR rateswere achieved in patients who received $\mathrm{SOF} / \mathrm{DCV} \pm \mathrm{RBV}$ andthosewho received $\mathrm{SOF} / \mathrm{SIM} \pm \mathrm{RBV}$. This is in agree with Babatin et al [27], who mentioned that SMV/SOF or DCV/SOF combinations are safe and highly effective in HCV genotype 4 treatment Pearlman et al [28], also found that a regimen of Simeprevir and sofosbuvir produced a significantly higher rate of SVR and was better tolerated, with a lower viral relapse rate, than a regimen of peginterferon, ribavirin, and sofosbuvir.

The rate of adverse events was significantly different among the studied groups with lowest rate in group 4 . The most common reported adverse events in group 1 were flu like illness and anemia. Flu like symptoms are related to use of interferon [29], whereas anemia is known to be frequent in ribavirin-inclusive combinations [30]. Ribavirin-induced anemia is a well described phenomenon [31].

In group 2, anemia, hyperbilirubinemia and fatigue were the most frequent side effects, while in group 3, hyperbilirubinemia and fatigue were the main adverse events. In group 4, only two adverse events have been reported; hyperbilirubinemia and anemia.

Hyper bilirubinemia during treatment with SMV/SOF and DCV/SOF was recorded also by Babatin et al [28].Hyperbilirubinemia during SOF/ SMV therapy was also documented Yosry et al [6]. These changes are transient and normalized during the course of treatment despite the continuation of DAAs.

According the practice guidelines during the study period sofosbuvir was not allowed for patients with severe renal impairment or with end-stage renal disease and hence patients with severe renal impairment were excluded from this study because $80 \%$ of sofosbuvir is excreted through the kidney [32].

Also, patients with active hepatocellular carcinoma (HCC) or recently treated HCC has been ruled out. Rates of HCC recurrence after 
DAAs were extremely variable in different studies [33]. The possibility that treatment with DAAs may favor tumor growth and spread in individual patients with active HCC foci is suggested by some observations [6].

In this study the high overall SVR was confirming the efficacy of DAA-based regimens, similar to COSMOS [34], ALLY-3 [27], and even to European [35] and North American [36] real-life studies. Oral therapy may be a reasonable option for patients with compensated cirrhosis as well as patients who failed to respond to previous therapy.

The current study had its own limitations. First, inclusion of IFN-based regimens, those are currently obsolete for HCV management. Second, the lack of evaluation of the newer generations of DAAs e.g. velpatasvir that seems effective in both compensated and decompensated HCV related cirrhosis. These because the period covered by the study was in the early era of HCV management by DAAs. The probability of selection bias among patients' enrolment to each therapeutic arm.

In conclusion, oral HCV SOF-based treatments are associated with high rates of SVR and a good tolerance for patients in real life.The combination of sofosbuvir with daclatasvir was associated with high cure rates in naïve, cirrhotic and treatment experienced patients. Regarding the safety of SOF-based oral therapy, in general, it was safe and well tolerated.

\section{DECLARATIONS}

Ethics approval and consent to participate: Approved

Competing interests: None declared

\section{Funding: None}

Authors' contributions: MA and TS formulated the research idea, prepared the study design, shared in the interpretation of collected data, and shared in the revision of the manuscript. TA and $\mathrm{OH}$ collected the research data, shared in interpretation and analysis of collected data. TZ and OA drafted the manuscript, shared in interpretation and analysis of collected data. ED revised and proofread the manuscript draft and shared in data analysis. All authors approved the final manuscript

Acknowledgements:Authors would like to thank all individuals working in the virology clinics in the participating centers
List of Abbreviations

HCV: Hepatitis C virus

CDC: Center for Disease Control

SOF: Sofosbuvir

PEG-IFN: Pegylated interferon

DAC: Daclatasvir

SIM: Simeprevir

SVR:Sustained virological response

DAAs:Direct-acting antivirals

RBV:Ribavirin

CTP: Child Turcotte Pugh

ALT:Alanine aminotransferase

AST:Aspartate aminotransferase

AFP:Alpha fetoprotein

HCV PCR:Hepatitis $C$ virus polymerase chain reaction

CBC:Complete blood count

INR:International normalized ratio

ESLD:End-stage liver disease

LT:Liver transplantation

HCC:Hepatocellular carcinoma

SPSS:Statistical Package for Social Sciences

EOT:End of treatment

\section{REFERENCES}

1.

Centers for Disease Control and Prevention.

Hepatitis C FAQs for health professionals. Available

at:http://www.cdc.gov/hepatitis/hcv/hcvfaq.htm.

Accessed October 27, 2016.

2.

Perz JF, Armstrong GL, Farrington LA, Hutin YJ, Bell BP. The contributions of hepatitis B virus and hepatitis $\mathrm{C}$ virus infections to cirrhosis and primary liver cancer worldwide. $J$ Hepatol 2006;45:529-538.

3. Manns MP, Wedemeyer H, Cornberg M. Treating viral hepatitis C: efficacy, side effects, and complications. Gut 2006;55(9):1350-9.

4. Pawlotsky JM. New hepatitis C therapies: the toolbox, strategies, and challenges. Gastroenterology 2014;146(5):1176-92.

5. Cha A, Budovich A. Sofosbuvir: a new oral once-daily agent for the treatment of hepatitis $\mathrm{C}$ virus infection. P T 2014;39(5):345-352.

6.

Yosry A, Eldeen H G, Medhat E, Mehrez M, Zayed N, Elakel W, et al. Efficacy and safety of sofosbuvir-based therapy in hepatitis $\mathrm{C}$ virus recurrence post living donor liver transplant: Areal life Egyptian experience. $J$ Med Virol 2019; 91:668-676 
7. Lavanchy D. Evolving epidemiology of hepatitis C virus. ClinMicrobiol Infect 2011;17:107-115

8. Lemoine, M, NayagamS,Thursz M. Viral hepatitis in resource-limited countries and access to antiviral therapies: current and future challenges.Future virologyFuture Virology2013; 8:4,371-380.

9. Paez Jimenez A, Mohamed MK, Eldin NS, Seif HA, El Aidi S, Sultan Y et al. Injection drug use is a risk factor for $\mathrm{HCV}$ infection in urban Egypt.PLoS ONE2009;4:e7193.

10. The European Association for the Study of the Liver. Clinical practice guidelines: EASL recommendations on treatment of hepatitis C. $J$ Hepatol 2015;63:199-236.

11. Cho Y,Cho EJ,Lee JH,Yu SJ,Yoon JH,Kim YJ. Sofosbuvir-based therapy for patients with chronic hepatitis C: Early experience of its efficacy and safety in Korea. Clinical and Molecular Hepatology 2015;21:358-36

12. Holzmann I, Tovo CV, Minmé R, Leal MP, Kliemann MP, Ubirajara C, et al.. Effectiveness of chronic hepatitis $\mathrm{C}$ treatment with directacting antivirals in the Public Health System in Brazil. Braz J Infect Dis 2018;22(4):317-322.

13. Lawitz E, Lalezari JP, Hassanein T, Kowdley KV, Poordad FF, Sheikh AM, et al. Sofosbuvir in combination with peginterferon alfa- $2 \mathrm{a}$ and ribavirin for non-cirrhotic, treatment-naive patients with genotypes 1,2 , and 3 hepatitis C infection: A randomised, double-blind, phase 2 trial.Lancet Infect Dis2013;13(5):401-08.

14. Bourlière M, Oules V, Ansaldi C, Adhoute X, Castellani P. Sofosbuvir as backbone of interferon free treatments.Dig Liver Dis2014;46:S212-20.

15. Lawitz E,Poordad F,Brainard DM,Hyland RH,An D,Dvory-Sobol H,et al. Sofosbuvir with peginterferon-ribavirin for 12 weeks in previously treated patients with hepatitis C genotype 2 or 3 and cirrhosis. Hepatology2015;61(3):769-75.

16. Wehmeyer MH,Ingiliz P,Christensen S,Hueppe D,Lutz T,Simon KG,et al. Real-world effectiveness of sofosbuvir-based treatment regimens for chronic hepatitis $\mathrm{C}$ genotype 3 infection: Results from the multicenter German hepatitis C cohort (GECCO-03). J Med Virol 2018; 90:304-312.

17. Mousa W and Mohamed M.G. Efficacy of Sofosbuvir Plus Ribavirin In Treatment Of Egyptian Patients With Chronic HCV Infection .Al-AzharAssiut Medical Journal (AAMJ) 2015;13(2): 207-213
18. American Association for the Study of Liver Diseases and the Infectious Diseases Society of America. Recommendations for testing, managing, and treating hepatitis C. <http://www.hcvguidelines.org/>; 2014 [accessed 2.06.14.]

19. EASL Clinical Practice Guidelines: management of hepatitis C virus infection. J Hepatol 2014; 60:392-420.

20. World Health Organization. Guidelines for screening, care and treatment of persons with hepatitis $\mathrm{C}$ infection. <http://www.who.int/hiv/pub/hepatitis/ hepatitisc-guidelines/en/>; 2014. [published April 2014 accessed June 2,2014].

21. European Association for the Study of the Liver. EASL recommendations on treatment of hepatitis C 2018.J Hepatol2018; 69:461-511.

22. Ahmed OA, Safwat E, Khalifa MO, Elshafie AI, Fouad MHA, Salama MM, et al. Sofosbuvir Plus Daclatasvir in Treatment of Chronic Hepatitis C Genotype 4 Infection in a Cohort of Egyptian Patients: An Experiment the Size of Egyptian Village. Int J Hepatol 2018;2018:1-5.

23. Omar H, El Akel W, Elbaz T, El Kassas M, Elsaeed K, El Shazly $\mathrm{H}$, et al. Generic daclatasvir plus sofosbuvir, with or without ribavirin, in treatment of chronic hepatitis $\mathrm{C}$ : real-world results from 18378 patients in Egypt. Aliment PharmacolTher47(3):421-431.

24. Kutala BK, Mouri F, Castelnau C, Bouton V, Giuily N, Boyer N, et al. Efficacy and safety of sofosbuvir-based therapies in patients with advanced liver disease in a real-life cohort. Hepat Med 2017 18;9:67-73.

25. Lawitz E, Matusow G, DeJesus E, Yoshida EM, Felizarta F, Ghalib R, et al. Simeprevir plus sofosbuvir in patients with chronic hepatitis $\mathrm{C}$ virus genotype 1 infection and cirrhosis: a phase 3 study (OPTIMIST-2). Hepatology 2016;64: 360-369.

26. Nelson DR, Cooper JN, Lalezari JP, Lawitz E, Pockros PJ, Gitlin N, et al. All-oral 12-week treatment with daclatasvir plus sofosbuvir in patients with hepatitis $\mathrm{C}$ virus genotype 3 infection: ALLY-3 phase III study. Hepatology 2015;61: 1127-1135.

27. Babatin MA,Alghamdi AS,Albenmousa A,Alaseeri A,Aljarodi M,Albiladi H,et al. Efficacy and Safety of Simeprevir or Daclatasvir in Combination With Sofosbuvir for the Treatment of Hepatitis C Genotype 4 Infection. $J$ ClinGastroenterol2018;52(5):452-457.

28. Pearlman BL,Ehleben C,Perrys M. The combination of simeprevir and sofosbuvir is 
more effective than that of peginterferon, ribavirin, and sofosbuvir for patients with hepatitis C-related Child's class A cirrhosis.Gastroenterology2015;148(4):762-70.

29. Manns MP, Wedemeyer H, Cornberg M. Treating viral hepatitis C: efficacy, side effects, and complications. Gut 2006;55(9):1350-9.

30. Tong MJ,Chang PW,Huynh TT,Rosinski AA,Tong LT. Adverse events associated with ribavirin in sofosbuvir-based therapies for patients with chronic hepatitis C: A community practice experience. J Dig Dis2016;17(2):11321.

31. Canonico PG, Kastello MD, Spears CT, Brown JR, Jackson EA, Jenkins DE. Effects of ribavirin on red blood cells. ToxicolApplPharmacol 1984; 74: $155-62$.

32. Desnoyer A, Pospai D, Le MP, Gervais A, Heurgue-Berlot A, Laradi A, et al. Pharmacokinetics, safety and efficacy of a full dose sofosbuvirbased regimen given daily in hemodialysis patients with chronic hepatitis C. $J$ Hepatol 2016;65:40-47.
33. Alberti A, Piovesan S. Increased incidence of liver cancer after successful DAA treatment of chronic hepatitis C: Fact or fiction? Liver Int 2017;37(6):802-808.

34. Lawitz E, Sulkowski MS, Ghalib R, RodriguezTorres M, Younossi ZM, Corregidor A, et al. Simeprevir plus sofosbuvir, with or without ribavirin, to treat chronic infection with hepatitis $\mathrm{C}$ virus genotype 1 in non-responders to pegylated interferon and ribavirin and treatmentnaive patients: the COSMOS randomised study. Lancet 2014;15:1756-65.

35. Pol S, Bourliere M, Lucier S, Hezode C, Dorival C, Larrey D, et al. Safety and efficacy of daclatasvir-sofosbuvir in HCV genotype 1mono-infected patients. J Hepatol 2017;66:3947.

36. Jensen DM, O’Leary JG, Pockros PJ, Sherman K, Kwo P, Mailliard M, et al. Safety and efficacy of sofosbuvir-containing regimens for hepatitis $\mathrm{C}$ : real world experience in a diverse, longitudinal observational cohort. Hepatology 2014;60:219-20. 